\title{
Genetic variation in meiotic behaviour and fertility in tetraploid Hyoscyamus muticus: correlation with diploid meiosis*
}

\author{
SANGEETA SRIVASTAVA, U. C. LAVANIA $†$ \& J. SYBENGA $\ddagger$ \\ Central Institute of Medicinal and Aromatic Plants Post: Ram Sagar Misra Nagar, Lucknow-226016 India and \\ $\ddagger$ Department of Genetics, Agricultural University Dreijenlaan 2, 6703 HA, Wageningen, The Netherlands
}

\begin{abstract}
Autotetraploidy was induced in 19 morphologically distinct genotypes of the medicinal solanaceous plant Hyoscyamus muticus (Egyptian henbane, $4 x=56$ ). The multivalent association frequencies at metaphase I of meiosis ranged from 0.328 to 0.628 and were positively correlated with the chiasmate association frequency in the diploid progenitors. The frequent absence of chiasmata in one of the two chromosome arms in most of the tetraploids was attributed to interference between the arms and to pairing partner exchange in one of the chromosome arms instead of around the centromers. The bivalent frequency in the tetraploids was positively correlated with pollen fertility and seed set. The latter ranged from 7.5 to 68.5 per cent. The asymmetry of the karyotype was not reflected in the distribution of open bivalents in the diploid. The regression coefficients of metaphase I chromosome associations over fertility in the tetraploid suggested that, in the range covered, one multivalent less resulted in an increase of about 12 per cent in seed set. The regression of open bivalent frequency in the diploid progenitor over seed set in the tetraploid suggested that one open bivalent more in the diploid would result in almost 18 per cent seed set in the tetraploid. It is concluded that the selection of diploid progenitors with high frequencies of open bivalents should enhance the fertility of the artificial polyploids in H. muticus.
\end{abstract}

Keywords: autotetraploid, diploid, fertility, Hyoscyamus muticus, meiosis.

\section{Introduction}

Artificial autotetraploids of the medicinal solanaceous plant Hyoscyamus muticus (Egyptian henbane) are superior to diploids in vigour and the production of secondary metabolites (Lavania, 1988), but highly variable in respect to pollen fertility and seed set, depending on the starting material (Lavania, 1986a). The reduced fertility of (artificial) autotetraploids may have its origin in developmental disturbance in gametes, embryo or endosperm caused by the physiological consequences of gene imbalance, or it may be due to meiotic irregularities resulting in aneuploidy. If the effects of aneuploidy on fertility are large compared with the effects of genetic imbalance, and if there is sufficient genetic variation, it is possible to enhance fertility by selecting the meiotic configurations which are conducive for regular chromosome disjunction. Usually, however, selection is on fertility directly and meiotic regularity is only a consequence.

\footnotetext{
*= CIMAP publication no. $40 / 91$.
}

$\dagger=$ Corresponding author.
In an autotetraploid of $H$. muticus, selection for fertility resulted in an increase of bivalent frequency (Lavania, 1986a, 1986b, 1988). The preliminary conclusion was that in this species the regulation of meiotic behaviour has a pronounced positive effect on fertility. The present study was set up to analyse the following. 1 The relation between meiotic chromosome behaviour and fertility in the tetraploid.

2 The correlation between mitotic chromosome characteristics and meiotic behaviour.

3 The correlation between diploid and tetraploid meiotic chromosome behaviour and tetraploid fertility. 4 Variation between tetraploids in chromosome association pattern and fertility.

A practical consequence of the experiment was that the genetic spectrum of available tetraploid genotypes was enlarged.

\section{Materials and methods}

Seeds were obtained from 19 morphologically distinct diploid genotypes of $H$. muticus $(2 n=2 x=28)$, representing three different main sources: (i) Lucknow (origi- 
nally from Egypt), (ii) Indore, and (iii) an advanced generation of a gamma-irradiated stock, reproduced by selfing. Shoot apices of fast growing seedlings at the 4-6 leaf stage were treated with a 0.2 per cent aqueous colchicine solution, continuously administered for $24 \mathrm{~h}$ in a cotton plug (Lavania, 1986b). Seeds were harvested from the $C_{0}$ plants and grown as the $C_{1}$ generation for the study of meiotic and fertility parameters.

Between 10 and 12 easily analysable metaphase I cells from each of 3-5 different anthers of the $C_{1}$ (a total of 50-60 cells for each genotype) were analysed using an acetocarmine squash technique (Fig. 1). One hundred cells of each of the diploid progenitors were studied.

Pollen fertility was established on the basis of pollen stainability in acetocarmine, considering stained pollen as fertile, and seed fertility as the percentage of filled seeds. Aneuploids were excluded from consideration.

The mitotic chromosomes were measured in camara lucida drawings made from acetocarmine squash preparations (Lavania et al., 1991) of root-tips of diploid seedlings. This method is satisfactory for the present purpose of correlating somatic chromosome characteristics with meiotic behaviour.
All configuration frequencies in the calculations were expressed as sets of two homologous chromosomes in the diploids and sets of four homologous chromosomes in the tetraploids. The frequency of quadrivalent pairing cannot be estimated directly from the observed configuration frequencies because an initial quadrivalent will not be maintained in the absence of sufficient chiasmata. The quadrivalent pairing frequency $f$ can be estimated from the ring quadrivalent, chain quadrivalent and trivalent frequencies according to Sybenga (1975a, b), on the assumptions that the two arms of the chromosomes pair and form chiasmata independently and that there is one point of pairing partner exchange. The frequency of bivalent pairing in the tetraploid equals $(1-f)$.

The frequency of chiasmate association $a$ and $b$ of the two average arms of the chromosomes may also be estimated from the meiotic configuration frequencies in tetraploids and diploids. It is possible in tetraploids to give equations for $a$ and $b$ after bivalent pairing and after quadrivalent pairing separately (Sybenga, 1975a, b). With positive interference the difference between $a$ and $b$ is overestimated, with negative interference the

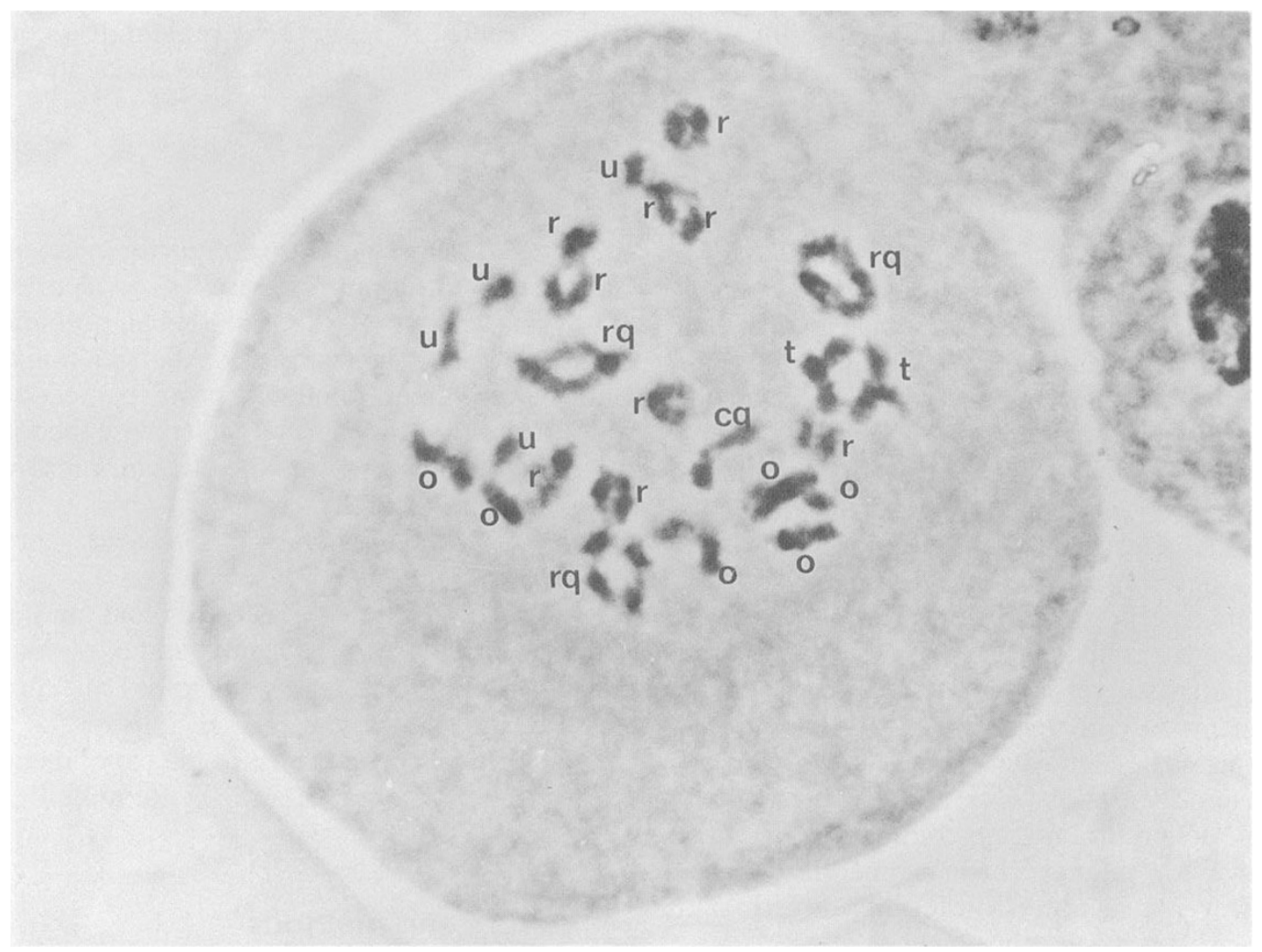

Fig. 1 Pollen mother cell of tetraploid Hyoscyamus muticus at diakinesis: (u) univalent; (r) ring bivalent; (o) open bivalent; (t) trivalent; $(\mathrm{cq})$ chain quadrivalent; $(\mathrm{rq})$ ring quadrivalent. Moderate squashing resulted in a preparation in which the configurations can be easily analysed microscopically but less so in a two-dimensional photomicrograph. 
difference is underestimated and with strong negative interference combined with close similarity beween the two arms, the discriminant in the formula is negative, and no solution is obtained. The best possible approximation then is assuming the two arms to be equal in chiasmate association.

\section{Results}

The general features of the mitotic chromosomes of $H$. muticus are given in Table 1 . The karyotype of $H$. muticus is rather asymmetric with relatively small chromosomes, ranging in size from 1.3 to $2.6 \mu \mathrm{m}$, and with long:short arm ratios ranging from 1.13 to 8.5 .

The frequencies of the different meiotic metaphase I configurations observed in the diploids and the corresponding tetraploids are shown in Table 2 . The distribution of open bivalents over cells, and the distribution of interstitial third chiasmata in ring ivalents over cells in a sample of diploids are given in Table 3. Meiotic and fertility parameters are compared in Table 4.

Meiosis is normal in diploids, with a low although not negligible frequency of univalents. This does not affect fertility as the distribution at anaphase is regular. At metaphase the chiasmata are mainly distal, but their actual location is difficult to determine due to the shortness and the compact morphology of the meiotic metaphase I chromosomes and the stretched appearance of the associated end segments in some bivalents. In a few genotypes $(5,10,12,13,15$, compare Table 3$)$ occasional additional chiasmata were seen in interstitial position in the larger ring bivalents, which then had three visible chiasmata. The two or three chromosome pairs with subacrocentric to acrocentric morphology might be expected to form open bivalents more often than the other chromosomes, and perhaps especially the smallest two (Table 1). This is not reflected in the distribution of open bivalent over cells, which follows a binomial distribution rather than a distribution with a peak at the classes of one and two open bivalents, expected to represent the two small acrocentric chromosomes (Table 2). The single case with a deviation from a binomial distribution (type 13) has an excess of cells with 4 and 5 open bivalents. Apparently, (sub)metacentric chromosomes form open bivalents almost as frequently as the more acrocentric chromosomes. With a reasonable chiasma frequency and in the absence of regular formation of univalents, this suggests that there is interference across the centromere.

In spite of the presence of several chromosomes with considerable arm length differences, in a number of genotypes the average two arms were concluded to be equal in chiasma frequency $(a / b=1)$ due to a negative discriminant in the formula for $a$ and $b$ (Table 4). In other genotypes the arm association frequencies were rather different (up to $a / b=1.5$ ). The individual estimates for $a$ and $b$ are given for the examples in Table 2. Although such estimates tend to be rather sensitive to variation in the univalent frequencies, there are clearly considerable differences between diploid genotypes in the patterns of interference between the arms.

The frequency of multivalents (quadrivalents and trivalents) varied between the tetraploids derived from the different diploid genotypes. It is striking that whereas the quadrivalents had hardly any interstitial chiasmata between the point of partner exchange and the centromere, which would result in branched configurations (frying pans, etc.), these were not infrequent in the trivalents. The ratios of the arm association frequencies $(a / b)$ are much larger in the tetraploids than in the diploids, i.e. one arm has a much higher chiasma frequency, which suggests that there is stronger positive interference in the tetraploids and perhaps little or no negative interference (Table 4).

A very striking other property of the tetraploids is that the estimated frequencies of multivalent pairing $(f)$ are almost consistently lower than the observed fre-

Table 1 Karyotype characteristics of Hyoscyamus muticus L. $(x=14)$

\begin{tabular}{llll}
\hline Chromosome & Type & $\begin{array}{l}\text { Approximate } \\
\text { arm ratio }\end{array}$ & $\begin{array}{l}\text { Approximate } \\
\text { length }(\mu \mathrm{m})\end{array}$ \\
\hline 1 (largest) & Submetacentric & 1.4 & 2.6 \\
2 & Submetacentric (SAT) & 1.4 & 2.4 \\
3 & Metacentric & 1.1 & 2.2 \\
4 and 5 & Subacrocentric & $2-3$ & 2.1 \\
6 & Submetacentric & 1.5 & 2 \\
7 & (Sub)acrocentric & 3.3 & 2 \\
$8-12$ & Subacrocentric & $1.8-2.4$ & $1.4-1.9$ \\
13 & Acrocentric & 5.7 & 1.4 \\
14 (smallest) & Acrocentric & 8.5 & 1.3 \\
\hline
\end{tabular}


Table 2 Frequency per cell of meiotic metaphase I configurations in 19 genotypes (ordered according to seed set, see Table 4) for diploid and tetraploid Hyoscyamus muticus L. $(x=14)$

\begin{tabular}{|c|c|c|c|c|c|c|c|c|c|c|c|c|c|}
\hline \multirow[b]{3}{*}{ Genotypes } & \multicolumn{3}{|l|}{ Diploid } & \multicolumn{10}{|c|}{ Tetraploid } \\
\hline & \multirow[b]{2}{*}{ Ring-II } & \multirow[b]{2}{*}{ Open-II } & \multirow[b]{2}{*}{ I-pair } & \multicolumn{2}{|c|}{ Quadrivalents } & \multicolumn{3}{|c|}{ Trivalents } & \multicolumn{2}{|c|}{ Bivalents } & \multirow{2}{*}{$\begin{array}{l}\text { Univalent } \\
\text { pairs }\end{array}$} & \multirow[b]{2}{*}{$f$} & \multirow{2}{*}{$\begin{array}{l}\text { Observed } \\
\text { multivalents }\end{array}$} \\
\hline & & & & Ring & Chain & Chain & f.pan* & $Y$ & Ring & Open & & & \\
\hline 1 & 11.86 & 1.97 & 0.17 & 4.7 & 2.4 & 0.7 & 0.50 & 0.50 & 4.2 & 4.9 & 1.3 & 0.607 & 0.608 \\
\hline 2 & 10.94 & 3.01 & 0.05 & 3.6 & 1.8 & 0.4 & 0.54 & 0.46 & 6.1 & 6.5 & 1.8 & 0.467 & 0.486 \\
\hline 3 & 10.36 & 3.36 & 0.28 & 2.9 & 1.6 & 0.2 & 0.40 & 0.30 & 6.9 & 8.8 & 1.5 & 0.379 & 0.385 \\
\hline 4 & 10.21 & 3.47 & 0.32 & 3.9 & 2.3 & 1.0 & 0.35 & 0.45 & 4.8 & 5.5 & 1.7 & 0.554 & 0.572 \\
\hline 5 & 9.95 & 3.80 & 0.25 & $2.8 \dagger$ & 1.4 & 0.4 & 0.40 & 0.40 & 6.9 & 8.7 & 1.6 & 0.369 & 0.386 \\
\hline 6 & 10.08 & 3.46 & 0.46 & 3.6 & 1.8 & 0.2 & 0.30 & 0.20 & 6.4 & 8.1 & 1.3 & 0.434 & 0.436 \\
\hline 7 & 9.38 & 4.31 & 0.31 & 3.4 & 2.1 & 0.4 & 0.55 & 0.45 & 5.7 & 6.8 & 1.7 & 0.484 & 0.439 \\
\hline 8 & 9.65 & 3.79 & 0.56 & 3.5 & 1.6 & 0.4 & 0.30 & 0.40 & 5.8 & 8.3 & 1.5 & 0.427 & 0.443 \\
\hline 9 & 9.39 & 4.19 & 0.42 & 3.3 & 1.5 & 0.5 & 0.20 & 0.30 & 6.8 & 8.4 & 1.2 & 0.400 & 0.414 \\
\hline 10 & 9.09 & 4.62 & 0.29 & 3.1 & 2.6 & 0.7 & 0.47 & 0.33 & 5.4 & 7.5 & 0.7 & 0.525 & 0.514 \\
\hline 11 & 8.64 & 5.16 & 0.20 & 3.5 & 1.8 & 0.7 & 0.50 & 0.40 & 6.0 & 7.2 & 1.0 & 0.471 & 0.493 \\
\hline 12 & 9.02 & 4.55 & 0.43 & 2.6 & 1.7 & 0.7 & 0.26 & 0.52 & 6.8 & 9.0 & 0.7 & 0.401 & 0.411 \\
\hline 13 & 9.18 & 4.45 & 0.37 & $2.5 \ddagger$ & 1.6 & 0.6 & 0.40 & 0.60 & 7.1 & 9.0 & 0.4 & 0.395 & 0.411 \\
\hline 14 & 8.95 & 4.39 & 0.66 & 2.2 & 1.7 & 0.4 & 0.23 & 0.30 & 8.4 & 9.1 & 0.9 & 0.346 & 0.342 \\
\hline 15 & 9.21 & 4.29 & 0.50 & $2.9 \S$ & 1.8 & 0.3 & 0.24 & 0.40 & 6.5 & 9.4 & 1.0 & 0.395 & 0.397 \\
\hline 16 & 9.18 & 3.93 & 0.89 & 2.4 & 1.4 & 0.3 & 0.25 & 0.25 & 6.9 & 11.4 & 0.5 & 0.324 & 0.328 \\
\hline 17 & 8.33 & 5.08 & 0.59 & 2.5 & 1.4 & 0.3 & 0.30 & 0.40 & 8.0 & 9.7 & 0.5 & 0.340 & 0.350 \\
\hline 18 & 8.69 & 4.32 & 0.99 & 2.2 & 1.8 & 0.3 & 0.40 & 0.30 & 8.0 & 10.0 & 0.0 & 0.365 & 0.357 \\
\hline 19 & 7.21 & 6.09 & 0.70 & 2.7 & 1.9 & 0.2 & 0.35 & 0.35 & 7.0 & 9.5 & 0.5 & 0.398 & 0.393 \\
\hline
\end{tabular}

*'Frying pan' = branched trivalent with closed segment, includes true 'frying pan' and 'birds cage' or 'convergent'.

$\dagger$ Includes 0.10 'figure 8 ' +0.20 'letter $x$ '.

†Includes 0.05 'figure 8 ' +0.15 'letter $x$ '.

$\S$ Includes 0.12 'figure 8 ' +0.35 'letter $x$ '.

quencies of multivalents at metaphase I, with only four exceptions. The parameters are very closely correlated, as expected, with a correlation coefficient of almost unity. The average multivalent frequencies observed at metaphase I, and the estimated frequencies at pachytene are very close together $(0.425$ versus 0.433$)$ but a $t$-test gave a significant difference $(t=3.447$; for 18 d.f. $P<0.003)$ because of the consistency of the difference. In theory the frequencies of observed multivalents, which depend on the formation of chiasmata, should always be lower than the pairing frequencies $f$. This suggests that the formation of chiasmata in different chromosome segments or arms is not independent. In addition, the actual frequency of quadrivalent pairing may be much closer to the theoretical 0.667 than the estimated frequency.

The correlations between fertility and meiotic parameters in the tetraploids are of special importance, and those between different parameters of the diploids and the tetraploids derived from them (Table 5).
As expected, there is a very close correlation between pollen fertility and seed set in the tetraploid: both are under close genetic control, and male and female fertility characteristics are closely correlated.

The negative correlations between overall multivalent frequencies and pollen, as well as seed fertility, are significant. A regression analysis suggests that one multivalent less results in about 12 per cent more seed set (regression equation: $y=111.8-168.4 x$ ). Because neither trivalent (contrary to expectation) nor chain quadrivalent frequencies are correlated with fertility, the ring quadrivalents must have a pronounced tendency to segregate anomalously. Differences between different organisms in respect of the meiotic segregation of different types of multivalents are a general phenomenon (Sybenga \& Rickards, 1987). One reason may be that the small, inflexible Hyoscyamus chromosomes do not often orient alternately and tend to have either adjacent or linear orientation. The latter carries a considerable risk of $3: 1$ segregation. 
Table 3 (a) Observed and expected frequency distributions of open bivalents in five genotypes of diploids of $\boldsymbol{H}$. muticus $\mathrm{L}$., four of which are types with additional interstitial chiasmata in ring bivalents. (b) Observed and expected frequency distributions of ring bivalents with a third (interstitial) chiasma in four of the five types in which they have been observed

\begin{tabular}{|c|c|c|c|c|c|c|c|c|c|}
\hline \multirow[b]{2}{*}{ Genotype } & \multirow[b]{2}{*}{ Cells } & \multicolumn{7}{|c|}{ Number of cells with $0-7$ open bivalents } & \multirow{2}{*}{$\begin{array}{l}\text { Average } \\
\text { frequency }\end{array}$} \\
\hline & & 0 & 2 & 3 & 4 & 5 & 6 & 7 & \\
\hline \multicolumn{10}{|l|}{ (a) } \\
\hline \multirow[t]{4}{*}{5} & 100 & & & & & & & & \multirow{3}{*}{0.543} \\
\hline & Observed & 3 & 6 & 20 & 41 & 26 & 2 & 0 & \\
\hline & Binomial & 0.4 & $3.4 \quad 12.4$ & 24.7 & 28.9 & 19.6 & 8.3 & 1.4 & \\
\hline & $\chi^{2}=3$ d.f. $=$ & $=2.89$; & $P=0.40$ & :ns & & & & & \\
\hline \multirow[t]{4}{*}{9} & 100 & & & & & & & & \multirow{3}{*}{0.597} \\
\hline & Observed & 2 & 9 & 16 & 36 & 16 & 19 & 2 & \\
\hline & Binomial & 0.2 & 1.68 .2 & 19.4 & 28.9 & 25.9 & 12.7 & 2.7 & \\
\hline & $\chi^{2} 4$ d.f. $=4$ & $.44 ; P$ & $=0.350$ & & & & & & \\
\hline \multirow[t]{3}{*}{12} & 97 & & & & & & & & \multirow{3}{*}{0.649} \\
\hline & Observed & 1 & 3 & 13 & 26 & 36 & 14 & 4 & \\
\hline & Binomial & 0.1 & 0.94 .3 & 13.9 & 25.8 & 28.8 & 17.9 & 4.7 & \\
\hline & $\chi^{2} 3$ d.f. $=1$ & $.48 ; P$ & $=0.688$ & & & & & & \\
\hline \multirow[t]{4}{*}{13} & 100 & & & & & & & & \multirow{3}{*}{0.636} \\
\hline & Observed & 0 & 0 & 9 & 40 & 39 & 6 & 3 & \\
\hline & Binomial & 0.1 & 0.95 .1 & 16.2 & 27.6 & 28.8 & 16.8 & 4.2 & \\
\hline & $\chi^{2} 3$ d.f. $=1$ & 1.33 & $P=0.010$ & differ & ence ver & ery sign & nifican & & \multirow{5}{*}{0.612} \\
\hline \multirow[t]{4}{*}{15} & 84 & & & & & & & & \\
\hline & Observed & 0 & $0 \quad 10$ & 14 & 22 & 20 & 16 & 2 & \\
\hline & Binomial & 0.1 & 1.16 .0 & 15.5 & 23.9 & 22.9 & 12.1 & 2.7 & \\
\hline & $\chi^{2} 4$ d.f. $=$ & $.23 ; F$ & $=0.814:$ & & & & & & \\
\hline (b) & & \multicolumn{7}{|c|}{$\begin{array}{l}\text { Number of cells with } 0-5 \text { ring bivalents with } \\
\text { third (interstitial) chiasma }\end{array}$} & \multirow{2}{*}{$\begin{array}{l}\text { Average } \\
\text { frequenc }\end{array}$} \\
\hline Genotype & Cells & 0 & 1 & 2 & 3 & 4 & 5 & & \\
\hline \multirow[t]{3}{*}{5} & 100 & & & & & & & & \multirow{3}{*}{0.151} \\
\hline & Observed & 26 & 42 & 32 & 0 & 0 & 0 & & \\
\hline & Binomial & 31.8 & 39.5 & 21.3 & 5.5 & 2.1 & - & & \\
\hline \multirow[t]{3}{*}{12} & 97 & & & & & & & & \multirow{3}{*}{0.180} \\
\hline & Observed & 13 & 46 & 38 & 0 & 0 & 0 & & \\
\hline & Binomial & 24.2 & 37.2 & 24.2 & 9.2 & 1.9 & - & & \\
\hline \multirow[t]{3}{*}{13} & 100 & & & & & & & & \multirow{3}{*}{0.241} \\
\hline & Observed & 7 & 24 & 62 & 7 & 0 & 0 & & \\
\hline & Binomial & 14.5 & 32.2 & 30.7 & 16.3 & 4.6 & & .2 & \\
\hline \multirow[t]{3}{*}{15} & 84 & & & & & & & & \multirow{3}{*}{0.293} \\
\hline & Observed & 0 & 5 & 70 & 9 & 0 & 0 & & \\
\hline & Binomial & 7.4 & 21.5 & 26.9 & 18.4 & 7.3 & & 1.8 & \\
\hline
\end{tabular}

The frequency of bivalents in the tetraploids is closely correlated with pollen and seed fertility: the formation of bivalents instead of quadrivalents has very positive consequences for fertility. The fact that the frequency of ring bivalents is not negatively correlated with the open bivalent frequency shows that, surpri- singly, in their formation, rings do not compete with open bivalents. In the discussion these and other complications will be considered again.

Several of the correlations between diploid and tetraploid meiotic behaviour are significant. However, the open bivalent frequency in diploids is not signifi- 
Table 4 Meiotic parameters of 19 genotypes (ordered according to seed set) for diploid, meiotic and fertility parameters for autotetraploid $H$. muticus L. $(x=14)$. (a) Estimated frequency of chiasmate association of the longer of the two arms of the average chromosome; (b) estimated frequency of chiasmate association of the shorter of the two arms. Only bivalents are considered

\begin{tabular}{|c|c|c|c|c|c|c|c|}
\hline \multirow[b]{3}{*}{ Genotype } & \multirow{2}{*}{\multicolumn{2}{|c|}{ Diploid }} & \multicolumn{5}{|c|}{ Tetraploid } \\
\hline & & & \multicolumn{3}{|c|}{ Chiasmate association } & \multirow{2}{*}{$\begin{array}{l}\text { Pollen } \\
\text { fertility } \\
(\%)\end{array}$} & \multirow{2}{*}{$\begin{array}{l}\text { Seed } \\
\text { set } \\
(\%)\end{array}$} \\
\hline & $\begin{array}{l}\text { Chiasmata } \\
\text { per bivalent }\end{array}$ & $a / b$ & $a$ & $b$ & $a / b$ & & \\
\hline 1 & 1.84 & 1.001 & 0.77 & 0.50 & 1.532 & 68.4 & 7.5 \\
\hline 2 & 1.78 & 1.245 & \multicolumn{2}{|c|}{0.667} & (1) & 59.3 & 12.0 \\
\hline 3 & 1.72 & (1) & 0.834 & 0.475 & 1.756 & 62.1 & 17.0 \\
\hline 4 & 1.71 & (1) & 0.695 & 0.551 & 1.261 & 77.4 & 18.5 \\
\hline 5 & $1.69(+0.08)^{*}$ & 1.193 & 0.830 & 0.469 & 1.769 & 65.1 & 19.0 \\
\hline 6 & 1.69 & 1.001 & 0.844 & 0.480 & 1.758 & 63.7 & 20.4 \\
\hline 7 & 1.65 & 1.261 & 0.751 & 0.526 & 1.428 & 57.4 & 22.7 \\
\hline 8 & 1.65 & 1.001 & 0.834 & 0.433 & 1.926 & 74.2 & 23.0 \\
\hline 9 & 1.64 & 1.123 & 0.864 & 0.469 & 1.842 & 84.2 & 39.1 \\
\hline 10 & $1.63(+0.18)^{*}$ & 1.336 & 0.904 & 0.449 & 2.013 & 82.6 & 39.1 \\
\hline 11 & 1.60 & 1.497 & 0.874 & 0.462 & 1.892 & 83.5 & 42.9 \\
\hline 12 & $1.61(+0.09)^{*}$ & 1.222 & 0.931 & 0.433 & 2.150 & 95.8 & 52.6 \\
\hline 13 & $1.63(+0.22)^{*}$ & 1.251 & 0.963 & 0.436 & 2.209 & 86.7 & 54.6 \\
\hline 14 & 1.59 & (1) & 0.905 & 0.507 & 1.785 & 87.7 & 56.5 \\
\hline 15 & $1.62(+0.15)^{*}$ & (1) & 0.897 & 0.428 & 2.096 & 87.1 & 57.9 \\
\hline 16 & 1.59 & (1) & 0.956 & 0.381 & 2.509 & 96.0 & 58.2 \\
\hline 17 & 1.55 & 1.261 & 0.950 & 0.456 & 2.083 & 91.1 & 58.3 \\
\hline 18 & 1.55 & (1) & 0.876 & 0.573 & 1.529 & 94.3 & 68.3 \\
\hline 19 & 1.47 & 1.500 & 0.949 & 0.437 & 2.172 & 94.1 & 68.5 \\
\hline
\end{tabular}

*Additional interstitial chiasmata.

(1) = Discriminant negative, difference between arms not to be estimated; ratio assumed to equal unity.

cantly correlated with trivalent frequency and chain quadrivalent frequency in the tetraploids. The univalent frequency in diploids, although not significantly correlated with chain quadrivalent frequency, is significantly correlated with trivalent frequency in the tetraploids and even more strongly with overall multivalent frequency, including rings. This suggests that genotypes with low chiasma frequencies (many univalents in the diploid) have a high level of multivalent breakdown. All break down into bivalents, but rings break down first into chain quadrivalents, which partly compensates for the loss of chains. Trivalents with univalents increase both from rings and chains but are very readily broken down to bivalents and univalents.

The open bivalent frequency in diploids is positively and significantly correlated with open bivalent frequency in tetraploids, but the correlation between univalent frequency in diploids and open bivalent frequency in tetraploids is stronger. Because multi- valent frequency in tetraploids is more strongly negatively correlated with univalent than with open bivalent frequency in the diploid, the high bivalent frequency in tetraploids is to a considerable extent due to low chiasma frequencies, with the univalent frequency in diploids giving a better indication of chiasma frequency. The way these low chiasma frequencies are translated into specific configurations is complex, because in the tetraploids trivalent formation is not correlated with univalent frequency in the diploids. Many more correlations have been estimated and found to be significant.

The correlations between diploid meiotic behaviour and tetraploid fertility factors are interesting. Apparently it is possible to preselect diploids for fertility at the tetraploid level, on the basis of diploid meiotic parameters. The open bivalent frequency in the diploid is positively correlated with pollen fertility and seed set in the tetraploid. The regression analysis suggests that 
Table 5 Correlation coefficients of pairs of parameters of Tables 2 and 4

\begin{tabular}{lrl}
\hline & Correlation & \multicolumn{1}{l}{$\begin{array}{l}\text { Significance } \\
\text { Parameters }\end{array}$} \\
& coefficient & $(P)$ \\
\hline Within tetraploids & & \\
Pollen fertility/seed set & 0.907 & $<10^{-6}$ \\
Multivalents/pollen fertility & -0.473 & $0.039^{*}$ \\
Multivalents/seed set & -0.660 & $0.002^{* *}$ \\
Chain IV/pollen fertility & -0.205 & $0.400 \mathrm{~ns}$ \\
Chain IV/seed set & -0.301 & $0.211 \mathrm{~ns}$ \\
Trivalents/pollen fertility & -0.169 & $0.400 \mathrm{~ns}$ \\
Trivalents/seed set & -0.357 & $0.134 \mathrm{~ns}$ \\
Open bivalents/pollen fertility & 0.625 & $0.004^{* *}$ \\
Open bivalents/seed set & 0.759 & $0.0002^{* * *}$ \\
Ring bivalents/pollen fertility & 0.480 & $0.037^{*}$ \\
Ring bivalents/seed set & 0.687 & $0.001^{* *}$ \\
Open bivalents/multivalents & -0.949 & $<10^{-6}$ \\
Ring bivalents/open bivalents & 0.820 & $0.0002^{* * *}$ \\
Diploids/tetraploids & & \\
Open bivalents diploid/pollen fertility tetraploid & 0.627 & $0.004^{* *}$ \\
Open bivalents diploid/seed set tetraploid & 0.770 & $0.0001^{* * *}$ \\
Chiasmata diploid/pollen fertility tetraploid & -0.759 & $0.0002^{* * *}$ \\
Chiasmata diploid/seed set tetraploid & -0.892 & $<10^{-6 * * *}$ \\
Chiasmata diploid/multivalents & 0.646 & $0.003^{* *}$ \\
Univalents diploid/pollen fertility tetraploid & 0.687 & $0.001^{* * *}$ \\
Univalents diploid/seed set tetraploid & 0.749 & $0.0002^{* * *}$ \\
Chiasmata diploid/multivalents & 0.646 & $0.003^{* *}$ \\
Open bivalents diploid/multivalents & -0.479 & $0.038^{*}$ \\
Open bivalents diploid/chain IV & -0.199 & $0.414 \mathrm{~ns}$ \\
Open bivalents diploid/trivalents & -0.210 & $0.388 \mathrm{~ns}$ \\
Open bivalents diploid/open bivalents tetraploid & 0.523 & $0.021^{*}$ \\
Univalents diploid/multivalents & -0.682 & $0.013^{*}$ \\
Univalents diploid/chain IV & -0.353 & $0.138 \mathrm{~ns}$ \\
Univalents diploid/trivalents & -0.629 & $0.004^{* *}$ \\
Univalents diploid/open bivalents tetraploid & 0.774 & $0.0001^{* * *}$ \\
\hline
\end{tabular}

one open bivalent more in the diploid results in an increase in seed set in the tetraploid of almost 18 per cent (regression equation: $y=-34.16+17.70 x$ ). The correlation between chiasma frequency in the diploid and pollen fertility and seed set in the tetraploid is negative and quite strong. Univalent frequency is positively and also strongly related to the tetraploid fertility parameters. The selection of diploid progenitors with relatively low chiasma frequencies is apparently favourable for tetraploid fertility.

\section{Discussion}

In several autogamous and allogamous species a correlation between chiasma frequency in diploids and derived tetraploids has been demonstrated (Morisson \& Rajathy, 1960; Hazarika \& Rees, 1967; Swami \& Thomas, 1968; Simonsen, 1973, 1975; Gopal \& Singh,
1969). Simonsen (1973, 1975) showed that in Lolium perenne and Festuca pratensis the variation in chiasma frequency observed in diploids and tetraploids is under polygenic genetic control. Polygenic genetic control of other aspects of meiotic behaviour in diploids and tetraploids, such as high bivalent or quadrivalent frequencies in tetraploids, has also been established in different species: Lolium perenne (Crowley \& Rees, 1968; Simonsen, 1973); Pennisetum typhoides (Arundhati et al., 1983); Trigonella foenum-graecum (Gopal \& Singh, 1979). The same is clearly true for $H$. muticus.

In earlier studies (Lavania, 1986a, 1986b) of a highly fertile autotetraploid of $\mathrm{H}$. muticus, high pollen and seed fertility appeared to result from apparently high bivalent frequencies, correlated with relatively low chiasma frequencies. The importance of relatively low chiasma frequencies in diploid progenitors for the fer- 
tility of autotetraploids has been demonstrated for a range of species (Lavania, 1991) including Arachis spp. (Singh, 1986) and Avena strigosa (Zadoo et al., 1989).

Meiotic behaviour is especially important in $H$. muticus because of its great effect on fertility. Physiological imbalance resulting from gene dose effects may have a greater effect on autotetraploid fertility than meiotic behaviour (Bosemark, 1967). The earlier conclusions on $\mathrm{H}$. muticus can be considerably extended in the present study in which a large number of different genotypes are involved. In the previous section several important correlations between the different pairing, chiasma frequency and fertility parameters and their importance have been mentioned.

The high negative correlation in the tetraploids between ring bivalent and multivalent frequencies and the high positive correlation between ring bivalents and fertility indicates that perhaps ring bivalents can be a breakdown product of multivalents. This has also been suggested for the same phenomenon in Avena strigosa by Zadoo et al. (1989). The explanation was that the point of pairing partner exchange, which is variable in autopolyploids, can occur in distal regions of the chromosomes where most of the chiasmata are normally formed. It then interferes with chiasma formation in the end segments of the arm involved. With a single point of partner exchange the other arm pairs normally and so does the proximal part of the first arm. In this situation and in the absence of normal chiasma interference (because there is not distal chiasma), an interstitial chiasma can be formed.

The large difference between the two arms of the average chromosomes in the tetraploids compared with the diploids would seem to be due to effects on the interference pattern. The estimates depend on the relative frequencies of open bivalents in comparison with ring bivalents and univalent pairs in diploids. In tetraploids the estimates of arm association frequencies depend on the frequencies of configurations with one arm associated compared with those with two or no arms associated. With large numbers of open bivalents derived from multivalent pairing as a consequence of pairing partner exchange in relatively distal segments, open bivalents (one arm associated) will be relatively frequent, and the estimated difference between arms will be large. Thus such estimates are not very representative of the real situation.

Interference increases the frequency of open bivalents and as such would be a favourable factor in tetraploid fertility. It cannot be directly estimated. The parameter most directly affected by interference is the ratio between arm association frequencies $a / b$. There is no significant correlation between the diploid and tetraploid ratios $(r=0.165 ; P=0.498)$, nor between the diploid ratio and tetraploid seed set $(r=0.233$; $P=0.337$ ). The latter would have been an interesting selection criterion. The correlation between this ratio in the tetraploid and tetraploid seed set, however, is positive and highly significant $(r=0.650 ; P=0.003)$.

The frequency of bivalents, in spite of the relatively high fertility, is still not as high as in $H$. niger (black henbane), which also has large differences between diploid and tetraploids in meiotic behaviour (Lavania et al., 1991). Apparently, different species within genera, although similar in some aspects of tetraploid behaviour, may be rather different in other aspects.

\section{Acknowledgements}

We express our gratitude to the Director, CIMAP, for the facilities provided and to CSIR, New Delhi, for offering a senior research fellowship to the first author.

\section{References}

ARUNDHATI, K., PANTULU, J. V. AND NARASINGA RAO, P. S. R. L. 1983. Effect of selection for seed set on meiotic chromosome behaviour in autotetraploid pearl millet. Z. Pflanzenz., 90 , 145-152.

BOSEMARK, N. 1967. Post-meiotic nuclear fragmentation and pollen sterility in autotetraploid sugarbeet. Hereditas, 57, 217-238.

CROWLEY, J. G. AND REES, H. 1968. Fertility and selection in tetraploid Lolium. Chromosoma, 24, 300-308.

GOPAL, J. AND SINGH, A. 1979. Meiotic behaviour and seed fertility in advanced generation autotetraploids of fenugreek. Indian J. Genet. Pl. Breeding, 39, 323-329.

HAZARIKA, M. H. AND REES, H. 1967. Genotypic control of chromosome behaviour in rye. $\mathrm{X}$. Chromosome behaviour and fertility in autotetraploids. Heredity, 22, 317-332.

LAVANIA, U. C. 1986a. High bivalent frequencies in artificial autopolyploids of Hyoscyamus muticus L. Can. J. Genet. Cytol., 28, 7-11.

LAVANIA, U. C. $1986 \mathrm{~b}$. Genetic improvement of Egyptian henbane, Hyoscyamus muticus L. through induced tetraploidy. Theor. Appl. Genet., 73, 292-298.

LAVANIA, U. C. 1988. Development of a fertile autotetraploid strain in Hyoscyamus muticus L. Trop. Agric., 65, 277-278.

LAVANIA, U. C. 1991. Polyploid breeding: meiosis in the diploid progenitor and its predictive value for fertility in the autotetraploid. Proc. Indian Natn, Sci. Acad., B57, 17-24.

LAVANIA, U. C., SRIVASTAVA, S. AND SYBENGA, J. 1991. Cytogenetics of improved fertility in artificial autotetraploids of Hyoscyamus niger L. Genome, 34, 190-194.

MORRISON, J. W. AND RAJHATHY, T. 1960. Chromosome behaviour in autotetraploid cereals and grasses. Chromosoma, 11, 297-309.

SIMONSEN, O. 1973. Cytogenetic investigations in diploid and autotetraploid populations of Lolium perenne $\mathrm{L}$. Hereditas, 75, 157-188. 
SIMONSEN, o. 1975. Cytogenetic investigations in diploid and autotetraploid populations of Festuca pratensis. Hereditas, 79, 73-108.

SINGH, A. K. 1986. Utilization of wild relatives in the genetic improvement of Arachis hypogaea L. 7. Autotetraploid production and prospects in interspecific breeding. Theor. Appl. Genet., 72, 164-169.

SWAMI, U. B. S. AND THOMAS, H. 1968. Chromosomal pairing in autotetraploid Avena. Z. Pflanzenz., 59, 163-170.

SYBENGA, J. 1975a. The quantitative analysis of chromosome pairing and chiasma formation based on the relative fre- quencies of MI configurations VII. Autotetraploids. Chromosoma, 50, 211-222.

Sybenga, J. 1975. Meiotic Configurations. Springer-Verlag, Berlin.

SYBENGA, J. AND RICKARDS, G. K. 1987. The orientation of multivalents at metaphase I: a workshop report. Genome, 29, 612-620.

ZADOO, S. N., CHOUBEY, R. N., GUPTA, S. K. AND SYBENGA, J. 1989. Meiotic chromosome association in diploid and tetraploid Avena strigosa Schrel. Genome, 32, 972-977. 